\title{
Article \\ Occipital Nerve Stimulation for Pain Modulation in Drug-Resistant Chronic Cluster Headache
}

\author{
Javier Díaz-de-Terán ${ }^{1,2,3,+}{ }^{\dagger}$ Javier A. Membrilla ${ }^{1,+}{ }^{\dagger}$ José Paz-Solís ${ }^{3,4}{ }^{\oplus}$, Iñigo de Lorenzo ${ }^{1}$, Javier Roa ${ }^{1}$, \\ Manuel Lara-Lara ${ }^{1,3}$, Alfonso Gil-Martínez ${ }^{2,3,5, *}$ and Exuperio Díez-Tejedor ${ }^{1,3}$
}

1 Neurology Department, University Hospital La Paz, 28046 Madrid, Spain; javierddt@gmail.com (J.D.-d.-T.); membrillaja@gmail.com (J.A.M.); pinigo2593@gmail.com (I.d.L.); javier.roa.escobar@gmail.com (J.R.); manuellaral@hotmail.com (M.L.-L.); exuperio.diez@salud.madrid.org (E.D.-T.)

2 CranioSPain Research Group, Departamento de Fisioterapia, Centro Superior de Estudios Universitarios La Salle (UAM), La Salle Campus Madrid, 28023 Madrid, Spain

3 La Paz Institute for Health Research (IdiPAZ), 28046 Madrid, Spain

4 Neurosurgery Department, University Hospital La Paz, 28046 Madrid, Spain; jfpaz@telefonica.net

5 Unit of Physiotherapy, University Hospital La Paz, 28046 Madrid, Spain

* Correspondence: alfonso.gil@lasallecampus.es; Tel.: +34-666-137-908

+ These authors contributed equally to this work.

check for updates

Citation: Díaz-de-Terán, J.; Membrilla, J.A.; Paz-Solís, J.; de Lorenzo, I.; Roa, J.; Lara-Lara, M.; Gil-Martínez, A.; Díez-Tejedor, E.

Occipital Nerve Stimulation for Pain Modulation in Drug-Resistant Chronic Cluster Headache. Brain Sci. 2021, 11, 236. https://doi.org/ 10.3390/brainsci11020236

Academic Editor: Andrea

Carmine Belin

Received: 26 December 2020

Accepted: 8 February 2021

Published: 13 February 2021

Publisher's Note: MDPI stays neutral with regard to jurisdictional claims in published maps and institutional affiliations.

Copyright: (c) 2021 by the authors. Licensee MDPI, Basel, Switzerland. This article is an open access article distributed under the terms and conditions of the Creative Commons Attribution (CC BY) license (https:/ / creativecommons.org/licenses/by/ $4.0 /)$.

\begin{abstract}
Occipital nerve stimulation (ONS) is a surgical treatment proposed for drug-resistant chronic cluster headache $(\mathrm{drCCH})$. Long-term series assessing its efficacy are scarce. We designed a retrospective observational study with consecutive sampling, evaluating the follow-up of $17 \mathrm{drCCH}$ patients who underwent ONS. Our main endpoint was the reduction the rate of attacks per week. We also evaluated the pain intensity through the Visual Analogue Scale (VAS), patient overall perceived improvement and decrease in oral medication intake. After a median follow-up of 6.0 years (4.5-9.0), patients decreased from a median of 30 weekly attacks to $22.5(5.6-37.5, p=0.012), 7.5$ at 1 year $(p=0.006)$ and 15.0 at the end of follow-up $(p=0.041)$. The VAS decreased from a median of 10.0 to $8.0(p=0.011)$ at three months, to $7.0(p=0.008)$ at twelve months and $7.0(p=0.003)$ at the end of the follow-up. A total of $23.5 \%$ had an overall perceived improvement of $\geq 70 \%$ at 3 months, $41.2 \%$ at 1 year and $27.8 \%$ at the end of follow-up. Reducing prophylactic oral medication was possible in $76.5 \%$ and it was stopped in $17.7 \%$. Triptan use decreased in all the responder patients and $17.7 \%$ stopped its intake. A total of $41.2 \%$ presented mild adverse events. In conclusion, our long-term experience suggests that ONS could be an interesting option for drCCH-selected patients, as it is a beneficial and minimally invasive procedure with no serious adverse events.
\end{abstract}

Keywords: cluster headache; chronic; refractory; drug-resistant; neuromodulation; occipital nerve stimulation

\section{Introduction}

Cluster headache $(\mathrm{CH})$, the most common trigeminal autonomic cephalalgia, is defined as the onset of severe but strictly unilateral pain, which can be orbital, supraorbital, temporal or any combination of these, lasting 15-180 min, with a frequency of 1-8 per day, accompanied by a sense of restlessness and autonomic features in the trigeminal area [1]. $\mathrm{CH}$ is classified into episodic and chronic forms based on whether cluster-bout periods are separated by pain-free intervals (out-of-bout periods) that last at least 3 months [2]. Typically, $\mathrm{CH}$ patients respond to the usual treatments; however, in some cases, they become drug-resistant chronic $\mathrm{CH}(\mathrm{drCCH})$ [3].

For those patients who are refractory to the standard treatments, neurostimulation is an encouraging opportunity. Sphenopalatine ganglion stimulation, occipital nerve stimulation (ONS) and deep brain stimulation of the hypothalamus have all been proposed as invasive neuromodulation treatments for cluster headache [4]. Within the options of 
neurostimulation, the ONS is a recommended treatment option according to different European guidelines and consensus [5,6].

The ONS is one of the safest and most attractive choices for patients suffering dr$\mathrm{CCH}$, given the risk of serious complications described after other advanced therapeutic interventions. For example, deep-brain stimulation (DBS) may cause the development of contralateral cluster headache, seizure due to electrode repositioning after trauma, deep electrode infection leading to sepsis, death and ventricular hemorrhage [7]. This therapy is effective at targeting peripheral structures implied in $\mathrm{CH}$ pathophysiology, reducing the frequency and intensity of attacks through the inhibition of nociceptive activity in c-fibers and a-delta fibers. PET studies have also proved the central mechanism of ONS to be effective at normalizing hypermetabolic brain areas implicated in the pain matrix [8].

Invasive ONS has been assessed for $\mathrm{CH}$ prevention in different small open-label studies [8-11]. According to the American Headache Society's evidence-based guidelines, there are not enough studies of occipital nerve stimulation, but the existing data suggest a benefit [12]. Due to the lack of strong supporting evidence for use of the ONS in patients with $\mathrm{CCH}$, we want to contribute our long-term experience in the Headache Unit of a third level hospital.

The primary objective of this study is to evaluate the result of ONS as a long-term therapy for patients with drCCH, with the reduction in weekly headache attacks at the end of follow-up as our primary endpoint.

\section{Materials and Methods}

\subsection{Study Population}

This was a retrospective, observational study with consecutive sampling carried out at the Neurology Department of a third-level hospital in Madrid, Spain. We conducted a review of accumulated patient data obtained during the course of standard medical practice. No prospective treatment assignments were made, and all assessments were made through routine standard of care. Patients consented to individually giving their clinical history and headache diary retrospective data collection prior to ONS surgery. The study was reviewed and approved by the local Ethics Committee for Clinical Research of a public reference hospital (PI-4996). All patient data were treated with confidentiality, in fulfillment of the Declaration of Helsinki [13].

All patients included were diagnosed as chronic $\mathrm{CH}$ by a headache specialist, according to the International Classification of Headache Disorders 2nd edition (ICHD-II) (code 3.1.2.) [14], and fulfilled the European Headache Federation diagnostic definition of refractory $\mathrm{CCH}$ [3]. All patients had brain magnetic resonance imaging performed, with results within normal limits. These patients were considered candidates for ONS, following the recommendations of the Spanish Society of Neurology [6]. Prior to ONS implantation, all patients were evaluated by a multidisciplinary team of headache specialists composed by neurologists, neurosurgeons, anesthesiologists and psychiatrists. Implant surgery took place from March 2008 to June 2020. A minimum follow-up of 2 years after definitive ONS implantation was necessary for inclusion. A flow-chart of patient selection is available in Figure 1.

\subsection{Variables and Definitions}

According to the usual clinical practice in our Headache Unit, patient evaluation was performed before and every 3 months after surgery. Demographic data, number of preventive oral treatments trials and other therapeutic techniques before ONS indication and nosological information, were collected. Headache history (frequency, duration and intensity), clinical features, analgesics and triptans intake were also measured. Attack frequency (days of pain per week, month and number of attacks per day) and intensity (measured through the visual analogue scale (VAS)) were compared at baseline (prior to ONS implantation) and in the follow-up period. Overall perceived improvement was stratified in three groups depending on patient global improvement: poor responder $<30 \%$; 
responder $30-50 \%$; 50-70\% good responder, super-responder $\geq 70 \%$. Follow-up was defined as the period from ONS implantation surgery to system removal or deactivation. If the ONS was still active at the time of this study, it was considered an ongoing follow-up.

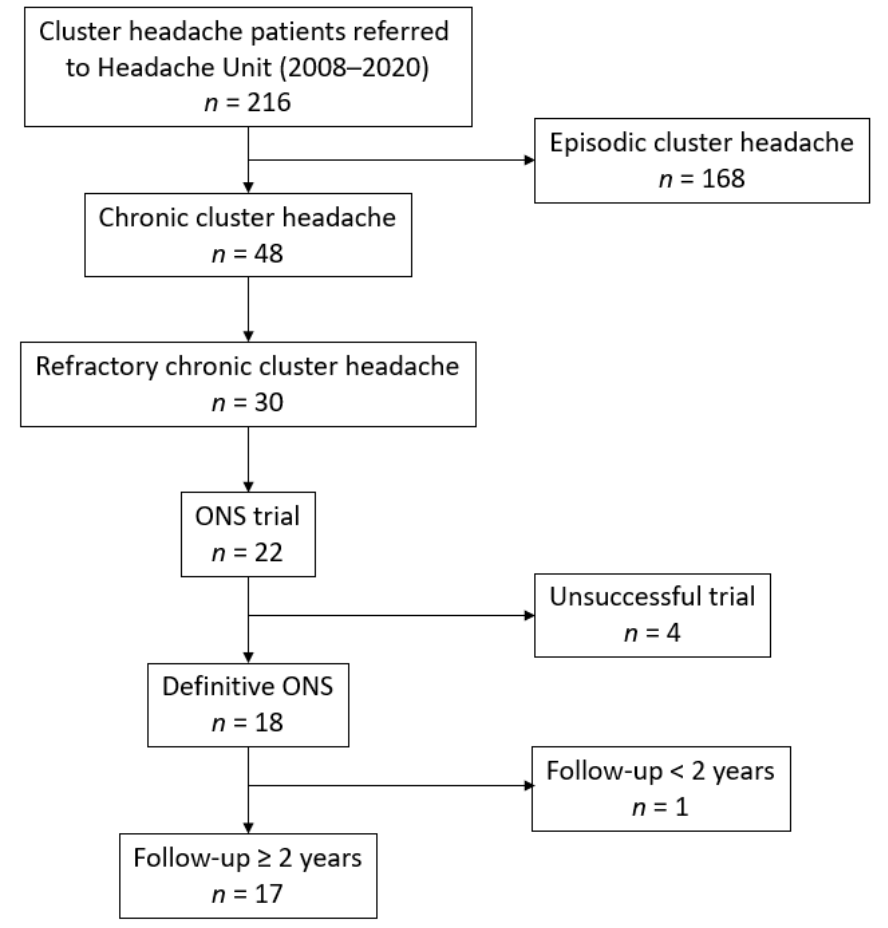

Figure 1. Flow-chart of patient selection (ONS: occipital nerve stimulation).

Our primary endpoint was the reduction in the number of attacks per week at the end of the follow-up. To study the evolution of the change in this variable after treatment, an analysis was also carried out three months and one year after the intervention.

\subsection{Data Collection}

Data were collected retrospectively by checking medical reports.

\subsection{Surgical Procedures}

This technique requires two phases: a trial phase (implant of the electrodes) and a definitive implantation of the generator and the leads, if they were previously removed after the trial phase [15-17].

1.-Trial phase: In prone position, with mild sedation, a vertical incision $1 \mathrm{~cm}$ above and below the occipital protuberance in the midline is practiced. Two eight-contact electrodes can then be implanted bilaterally through a Tuohy needle (with ultrasound or x-ray control) in an epiphascial fashion, covering the major and minor occipital nerves. The patient feels a paresthesia that radiates towards the vertex bilaterally. If the electrodes are to be left in the trial phase, the incision is lengthened to $4 \mathrm{~cm}$ and the leads are anchored in the fascia, leaving an external cable that will be tunneled subcutaneously along the cervical midline to a mid-dorsal level. Once the trial phase has passed (2-7 weeks), and if it is successful (pain improvement $>50 \%$ ), the leads are removed, or the external cable is cut, if it has been tunneled, leaving the leads implanted;

2.-Definitive phase: This can be done under general anesthesia (which is more comfortable for the patient) or with sedation. The patient can then be placed in prone position if the electrodes have been left previously, the nuchal incision is opened and the cable that was previously cut is removed. Another extension cable is connected to the buttock or abdominal region, where it is connected to the rechargeable generator. If the leads and generator are going to be placed all the way, the Trentmant technique is used [18], 
in a supine position, with the head lateralized, a medial and retro-mastoid incision is done, and the electrodes that are tunneled to the sub-clavicular region (there is no extension cable) are placed.

The electrodes are eight-contact electrodes, with a separation between contacts of $4 \mathrm{~mm}$, so that the stimulating electric field is wider. The implanted generators are rechargeable devices with an independent current control manufactured by Boston Scientific, CA. Stimulation parameters are programmed contacts, 3-4 cathodes and 1-2 anodes, pulse width of 250 us and frequency of $60 \mathrm{~Hz}$. The stimulation is continuous, although the patient can change the intensity of the stimulation on demand, according to his/her needs. The two sides of the head can be independently adjusted by the patient.

\subsection{Statistical Analysis}

Data analysis was performed using the Statistics Package for Social Science (SPSS 23.00-IBM, NY, USA). Nominal variables were reported as percentages and compared using a two-tailed Chi-square or Fisher test, when applicable. A two-tailed ShapiroWilk test for fewer than 30 participants was applied to examine whether the continuous quantitative variables followed a Gaussian distribution. Continuous quantitative variables were reported as mean \pm standard deviation (SD) if they followed a Gaussian distribution; otherwise, they were represented as median \pm interquartile range (IR). The Wilcoxon signed rank test was used to compare the median of two independent groups. If means were used, the independent samples $t$-test was used. Statistical significance was set at $p<0.05$ and Confidence Interval was established at 95\%.

\section{Results}

\subsection{Patients Characteristics}

As is depicted in Figure 1, twenty-two patients with drCCH underwent ONS trial, with 4/22 (18.2\%) not presenting significant improvement and being dismissed for definitive surgery. Clinical characteristics of these patients are shown in Table 1 . The remaining $18 / 22$ patients $(81.8 \%)$ had a positive result in the trial phase and proceeded to the definitive phase. One of them did not have a minimum follow-up of 2 years (the definitive ONS surgery was performed 4 weeks before this study). Of the lasting 17 patients, 10 were men $(58.8 \%)$. Mean age at the time of surgery was $41.2 \pm 8.7$ years. Patients with $\mathrm{CH}$ had a mean of $12.7 \pm 12.6$ years since diagnosis. All patients were drug-resistant and $4.5 \pm 1.7$ oral preventive treatments were tried prior to ONS surgery indication according to current guidelines [5,6]. All patients underwent treatment trial with maximum tolerated doses of verapamil, topiramate, lithium and at least one more preventive oral drug (baclofen, valproic acid), as well as oral steroids. Greater occipital nerve (GON) infiltration was performed in $9 / 17$ (52.9\%), four of them and 4/17 (23.5\%) were treated with onabotulinum toxin A (OnabotA) as well. OnabotA without GON infiltration was tried in 2/17 (11.8\%). One patient $(5.9 \%)$ was treated with transcutaneous electrical nerve stimulation and radiofrequency thermocoagulation of the sphenopalatine ganglion prior to ONS surgery. No patient underwent sphenopalatine ganglion stimulation. Further data are displayed in Table 2.

The median of follow-up after ONS surgery was 6.0 years (4.5-9.0). In 8/17 (47.1\%) patients, the ONS is still activated and follow-up is ongoing. The remaining 9/17 (52.9\%) patients had their follow-up ended by ONS deactivation $(2 / 17,11.8 \%)$ or removal $(7 / 18$, $41.2 \%)$. See Table 3 for further data. 
Table 1. Epidemiological and nosological characteristics of cluster headache patients who did not improve in the occipital nerve stimulation trial.

\begin{tabular}{|c|c|c|c|c|c|c|c|c|c|}
\hline \multirow[b]{2}{*}{ Age } & \multirow[b]{2}{*}{ Gender } & \multirow[b]{2}{*}{$\begin{array}{l}\text { Duration of } \\
\text { CH (Years) }\end{array}$} & \multirow{2}{*}{$\begin{array}{c}\text { Duration of } \\
\text { Chronic CH } \\
\text { (Years) }\end{array}$} & \multirow{2}{*}{$\begin{array}{c}\text { Preventive Oral } \\
\text { Treatment Trials } \\
\text { Prior to ONS }\end{array}$} & \multirow{2}{*}{$\begin{array}{c}\text { Therapeutic } \\
\text { Techniques } \\
\text { Prior to } \\
\text { ONS }\end{array}$} & \multicolumn{3}{|c|}{ Prior to ONS Trial (Baseline) } & \multirow{2}{*}{$\begin{array}{c}\text { Time of } \\
\text { ONS } \\
\text { Trial } \\
\text { (Weeks) }\end{array}$} \\
\hline & & & & & & $\begin{array}{l}\text { Days of Pain } \\
\text { per Month }\end{array}$ & $\begin{array}{l}\text { Attacks } \\
\text { per Day }\end{array}$ & $\begin{array}{c}\text { Attack } \\
\text { VAS Score } \\
\end{array}$ & \\
\hline 37 & Female & 3 & 1 & 3 & None & 20 & 1 & 8 & 3 \\
\hline 34 & Male & 23 & 9 & 3 & None & 30 & 10 & 10 & 7 \\
\hline 38 & Female & 14 & 11 & 3 & OnabotA & 30 & 8 & 10 & 3 \\
\hline 36 & Male & 8 & 5 & 4 & None & 30 & 2 & 10 & 2 \\
\hline
\end{tabular}

$\mathrm{CH}$ : cluster headache, ONS: occipital nerve stimulator, VAS: visual analogue scale, OnabotA: onabotulinumtoxin A.

Table 2. Epidemiological and nosological characteristics of cluster headache patients treated with occipital nerve stimulator.

\begin{tabular}{|c|c|c|c|c|c|c|c|c|c|}
\hline \multirow{2}{*}{$\begin{array}{l}\text { Patient } \\
\text { No. }\end{array}$} & \multirow[b]{2}{*}{ Age } & \multirow[b]{2}{*}{ Gender } & \multirow{2}{*}{$\begin{array}{c}\text { Duration } \\
\text { of } \mathrm{CH} \\
\text { (Years) }\end{array}$} & \multirow{2}{*}{$\begin{array}{l}\text { Duration } \\
\text { of Chronic } \\
\text { CH (Years) }\end{array}$} & \multirow{2}{*}{$\begin{array}{c}\text { Preventive Oral } \\
\text { Treatment Trials } \\
\text { Prior to ONS }\end{array}$} & \multirow{2}{*}{$\begin{array}{l}\text { Therapeutic } \\
\text { Techniques } \\
\text { Prior to ONS }\end{array}$} & \multicolumn{3}{|c|}{ Prior to ONS (Baseline) } \\
\hline & & & & & & & $\begin{array}{l}\text { Days of Pain } \\
\text { per Month }\end{array}$ & $\begin{array}{l}\text { Attacks } \\
\text { per Day }\end{array}$ & $\begin{array}{c}\text { Attack } \\
\text { VAS Score }\end{array}$ \\
\hline 1 & 54 & Female & 10 & 7 & 4 & $\begin{array}{c}\text { OnabotA, } \\
\text { GON TENS, } \\
\text { SPG RFT, } \\
\text { GON block }\end{array}$ & 30 & 4 & 9 \\
\hline 2 & 31 & Female & 4 & 2 & 3 & GON block & 30 & 1 & 10 \\
\hline 3 & 36 & Female & 17 & 11 & 6 & GON block & 30 & 10 & 10 \\
\hline 4 & 49 & Female & 31 & 22 & 6 & GON block & 30 & 1 & 10 \\
\hline 5 & 45 & Male & 33 & 25 & 5 & GON block & 30 & 5 & 10 \\
\hline 6 & 39 & Female & 23 & 16 & 3 & None & 30 & 9 & 8 \\
\hline 7 & 61 & Male & 44 & 10 & 4 & None & 30 & 2 & 10 \\
\hline 8 & 34 & Female & 2 & 1 & 5 & None & 30 & 4 & 9 \\
\hline 9 & 37 & Female & 3 & 2 & 3 & OnabotA & 30 & 16 & 10 \\
\hline 10 & 31 & Male & 4 & 3 & 4 & None & 10 & 1 & 10 \\
\hline 11 & 41 & Male & 4 & 3 & 3 & None & 30 & 14 & 10 \\
\hline 12 & 43 & Male & 4 & 2 & 8 & OnabotA & 30 & 3 & 10 \\
\hline 13 & 42 & Male & 6 & 4 & 3 & None & 30 & 2 & 9 \\
\hline 14 & 33 & Male & 4 & 1 & 3 & GON block & 30 & 7 & 10 \\
\hline 15 & 31 & Male & 9 & 6 & 4 & $\begin{array}{l}\text { GON block, } \\
\text { OnabotA }\end{array}$ & 30 & 3 & 10 \\
\hline 16 & 43 & Male & 7 & 5 & 8 & $\begin{array}{l}\text { Gon block, } \\
\text { OnabotA }\end{array}$ & 30 & 3 & 10 \\
\hline 17 & 51 & Male & 11 & 6 & 5 & $\begin{array}{l}\text { GON block, } \\
\text { OnabotA }\end{array}$ & 30 & 5 & 10 \\
\hline
\end{tabular}

Total number of headache attacks per day in patient's diary. Number of headache cluster attacks was 8, remaining headaches had migraine or tension-type headache characteristics. No.: number, $\mathrm{CH}$ : cluster headache, ONS: occipital nerve stimulator, VAS: visual analogue scale, OnabotA: onabotulinumtoxin A, GON: greater occipital nerve, TENS: transcutaneous electrical nerve stimulation, SPG: sphenopalatine ganglion, RFT: radiofrequency thermocoagulation.

\subsection{ONS Effect on Number of Weekly CH Attacks}

ONS successfully decreased the number of weekly $\mathrm{CH}$ attacks (see Figure 2). Prior to surgery, the median number of attacks per week was 30.0 (18.8-60.0). Three months after this intervention, the median number of weekly attacks decreased to 22.5 (5.6-37.5, $p=0.012$ ). The maximum of the median number of attacks reductions was registered one year after ONS surgery, accounting for 7.5 attacks per week $(1.6-41.3, p=0.006)$. At the end of follow-up, the weekly number of $\mathrm{CH}$ attacks had a median of $15.0(0.4-33.8, p=0.041)$. A total of $3 / 17$ (17.7\%) patients had a cluster headache become episodic at the end of the follow-up. 
Table 3. Follow-up after occipital nerve stimulator.

\begin{tabular}{|c|c|c|c|c|c|c|c|c|c|c|c|c|c|c|}
\hline \multirow[b]{2}{*}{$\begin{array}{l}\text { Patient } \\
\text { No. }\end{array}$} & \multirow[b]{2}{*}{$\underset{*}{\text { Follow-Up }}$} & \multirow[b]{2}{*}{$\begin{array}{l}\text { Adverse } \\
\text { Effects }\end{array}$} & \multicolumn{4}{|c|}{3 Months after ONS } & \multicolumn{4}{|c|}{1 Year after ONS } & \multicolumn{4}{|c|}{ At the End of Follow-Up } \\
\hline & & & $\begin{array}{c}\text { Days of } \\
\text { Pain per } \\
\text { Month }\end{array}$ & $\begin{array}{l}\text { Attacks } \\
\text { per Day }\end{array}$ & $\begin{array}{l}\text { Attack } \\
\text { VAS } \\
\text { Score }\end{array}$ & $\begin{array}{c}\text { Overall } \\
\text { Perceived } \\
\text { Improve- } \\
\text { ment }\end{array}$ & $\begin{array}{l}\text { Days of } \\
\text { Pain per } \\
\text { Month }\end{array}$ & $\begin{array}{l}\text { Attacks } \\
\text { per Day }\end{array}$ & $\begin{array}{l}\text { Attack } \\
\text { VAS } \\
\text { Score }\end{array}$ & $\begin{array}{c}\text { Overall } \\
\text { Perceived } \\
\text { Improve- } \\
\text { ment }\end{array}$ & $\begin{array}{l}\text { Days of } \\
\text { Pain per } \\
\text { Month }\end{array}$ & $\begin{array}{l}\text { Attacks } \\
\text { per Day }\end{array}$ & $\begin{array}{l}\text { Attack } \\
\text { VAS } \\
\text { Score }\end{array}$ & $\begin{array}{c}\text { Overall } \\
\text { Perceived } \\
\text { Improve- } \\
\text { ment }\end{array}$ \\
\hline 1 & $\begin{array}{c}4 \text { years } \\
\text { (deactivated) }\end{array}$ & None & 3 & 1 & 3 & $>70 \%$ & 3 & 1 & 3 & $>70 \%$ & 9 & $30 \mu$ & 4 & $<30 \%$ \\
\hline 2 & $\begin{array}{c}5 \text { years } \\
\text { (deactivated) }\end{array}$ & $\begin{array}{l}\text { Electrode } \\
\text { migration }\end{array}$ & 1 & 1 & 10 & $>70 \%$ & 1 & 1 & 10 & $>70 \%$ & 30 & 1 & 10 & $<30 \%$ \\
\hline 3 & $\begin{array}{c}5 \text { years } \\
\text { (removed) }\end{array}$ & None & 30 & 10 & 10 & $<30 \%$ & 30 & 10 & 10 & $<30 \%$ & 30 & 10 & 10 & $<30 \%$ \\
\hline 4 & $\begin{array}{c}12 \text { years } \\
\text { (ongoing) }\end{array}$ & $\begin{array}{l}\text { Posttraumatic } \\
\text { disconnection } \\
\text { (reintervention } \\
\text { needed) }\end{array}$ & 0 & 0 & NA & $>70 \%$ & 0 & 0 & $\mathrm{NA}$ & $>70 \%$ & $\begin{array}{l}\text { Once } \\
\text { every } 3 \\
\text { months }\end{array}$ & $\begin{array}{l}\text { Once } \\
\text { every } 3 \\
\text { months }\end{array}$ & 3 & $>70 \%$ \\
\hline 5 & $\begin{array}{c}9 \text { years } \\
\text { (ongoing) }\end{array}$ & $\begin{array}{l}\text { Mild pain on } \\
\text { surgery site }\end{array}$ & 30 & 5 & 10 & $<30 \%$ & 15 & 5 & 6 & $30-50 \%$ & $\begin{array}{l}\text { Once } \\
\text { every } 3 \\
\text { months }\end{array}$ & $\begin{array}{l}\text { Once } \\
\text { every } 3 \\
\text { months }\end{array}$ & 6 & $>70 \%$ \\
\hline 6 & $\begin{array}{c}8 \text { years } \\
\text { (removed) }\end{array}$ & None & 30 & 9 & 7 & $<30 \%$ & 30 & 9 & 7 & $<30 \%$ & 30 & 9 & 7 & $<30 \%$ \\
\hline 7 & $\begin{array}{l}10 \text { years } \\
\text { (ongoing) }\end{array}$ & None & 30 & 2 & 7 & $30-50 \%$ & 30 & 2 & 7 & $30-50 \%$ & 30 & 2 & 7 & $30-50 \%$ \\
\hline 8 & $\begin{array}{c}3 \text { years } \\
\text { (removed) }\end{array}$ & None & 30 & 4 & 7 & $<30 \%$ & 30 & 6 & 9 & $<30 \%$ & 30 & 6 & 9 & $<30 \%$ \\
\hline 9 & $\begin{array}{c}7 \text { years } \\
\text { (ongoing) }\end{array}$ & $\begin{array}{l}\text { Electrode } \\
\text { migration }\end{array}$ & 30 & 5 & 6 & $30-50 \%$ & 0 & 0 & NA & $>70 \%$ & 0 & 0 & NA & $>70 \%$ \\
\hline 10 & $\begin{array}{c}9 \text { years } \\
\text { (removed) }\end{array}$ & None & 30 & 5 & 10 & $<30 \%$ & 30 & 1 & 10 & $<30 \%$ & 30 & 1 & 7 & $<30 \%$ \\
\hline 11 & $\begin{array}{c}6 \text { years } \\
\text { (ongoing) }\end{array}$ & None & 30 & 1 & 6 & $50-70 \%$ & 30 & 10 & 8 & $30-50 \%$ & 30 & 2 & 10 & $30-50 \%$ \\
\hline 12 & $\begin{array}{c}5 \text { years } \\
\text { (ongoing) }\end{array}$ & $\begin{array}{l}\text { Surgical site } \\
\text { infection }\end{array}$ & 30 & 1 & 6 & $30-50 \%$ & 30 & 1 & 7 & $30-50 \%$ & 30 & 2 & 8 & $30-50 \%$ \\
\hline 13 & $\begin{array}{c}2 \text { years } \\
\text { (removed) }\end{array}$ & $\begin{array}{l}\text { Surgical site } \\
\text { infection }\end{array}$ & 20 & 2 & 9 & $30-50 \%$ & 30 & 2 & 10 & $<30 \%$ & 30 & 2 & 10 & $<30 \%$ \\
\hline 14 & $\begin{array}{l}12 \text { years } \\
\text { (ongoing) }\end{array}$ & None & 15 & 1 & 5 & $>70 \%$ & 5 & 3 & 5 & $>70 \%$ & 3 & 1 & 5 & $>70 \% \S$ \\
\hline 15 & $\begin{array}{c}3 \text { years } \\
\text { (removed) \# }\end{array}$ & None & 30 & 3 & 10 & $<30 \%$ & 10 & 3 & 5 & $>70 \%$ & $\begin{array}{c}\text { Once } \\
\text { every } 6 \\
\text { months }\end{array}$ & 1 & 5 & $>70 \%$ \\
\hline 16 & $\begin{array}{c}5 \text { years } \\
\text { (removed) }\end{array}$ & $\begin{array}{l}\text { Electrode } \\
\text { infection }\end{array}$ & 30 & 3 & 10 & $<30 \%$ & 10 & 1 & 5 & $>70 \%$ & 30 & 1 & 5 & $30-50 \%$ \\
\hline 17 & $\begin{array}{c}7 \text { years } \\
\text { (ongoing) }\end{array}$ & None & 30 & 5 & 10 & $<30 \%$ & 30 & 5 & 10 & $<30 \%$ & 30 & 3 & 3 & $30-50 \%$ \\
\hline
\end{tabular}

No.: number, ONS: occipital nerve stimulator, VAS: visual analogue scale, OnabotA: onabotulinumtoxin A, NA: not applicable. * Time from ONS placement to ONS deactivation or removal. Total number of headache attacks per day in patient's diary. Number of headache cluster attacks was 8 , remaining headaches had migraine or tension-type headache characteristics. $\mu$ Total number of headache attacks per day in patient's diary. Number of headache cluster attacks was 8 , remaining headaches had trigeminal neuralgia characteristics. § Cointervention: OnabotA started several years after ONS. \# Removal performed by patient decision.

\subsection{ONS Effect on Pain Severity}

The evolution of VAS of $\mathrm{CH}$ attacks after ONS was favorable. From a median of $10.0(9.5-10.0)$ at baseline, VAS decreased after surgery to $8.0(6.0-10.0, p=0.011)$ at three months, to $7.0(5.0-10.0, p=0.008)$ at twelve months and $7.0(5.0-9.8, p=0.003)$ at the end of follow-up.

\subsection{Overall Perceived Improvement}

Patients were asked to rate their improvement after ONS surgery as under $30 \%$, from 30 to $50 \%$, from 50 to $70 \%$ or greater than $70 \%$ at different follow-up times (see Figure 3). The rate of super-responders (overall perceived improvement greater than $70 \%$ ) was $23.5 \%$ $(4 / 17)$ at 3 months and of $41.2 \%(7 / 17)$ after one year. An interesting fact is that $5 / 17$ (29.4\%) of individuals still were super-responsive at the end of follow-up. A more modest response (improvement of 30\% to 50\%) was seen in 4/17 (23.5\%) both at 3 months and at 1 year, and $6 / 17(35.3 \%)$ at the end of follow-up. Finally, the lesser improvement (under $30 \%)$ occurred in $8 / 17(47.1 \%)$ at 3 months, in $6 / 17(35.3 \%)$ at 1 year and in $7 / 17(41.2 \%)$ at the end of follow-up. 


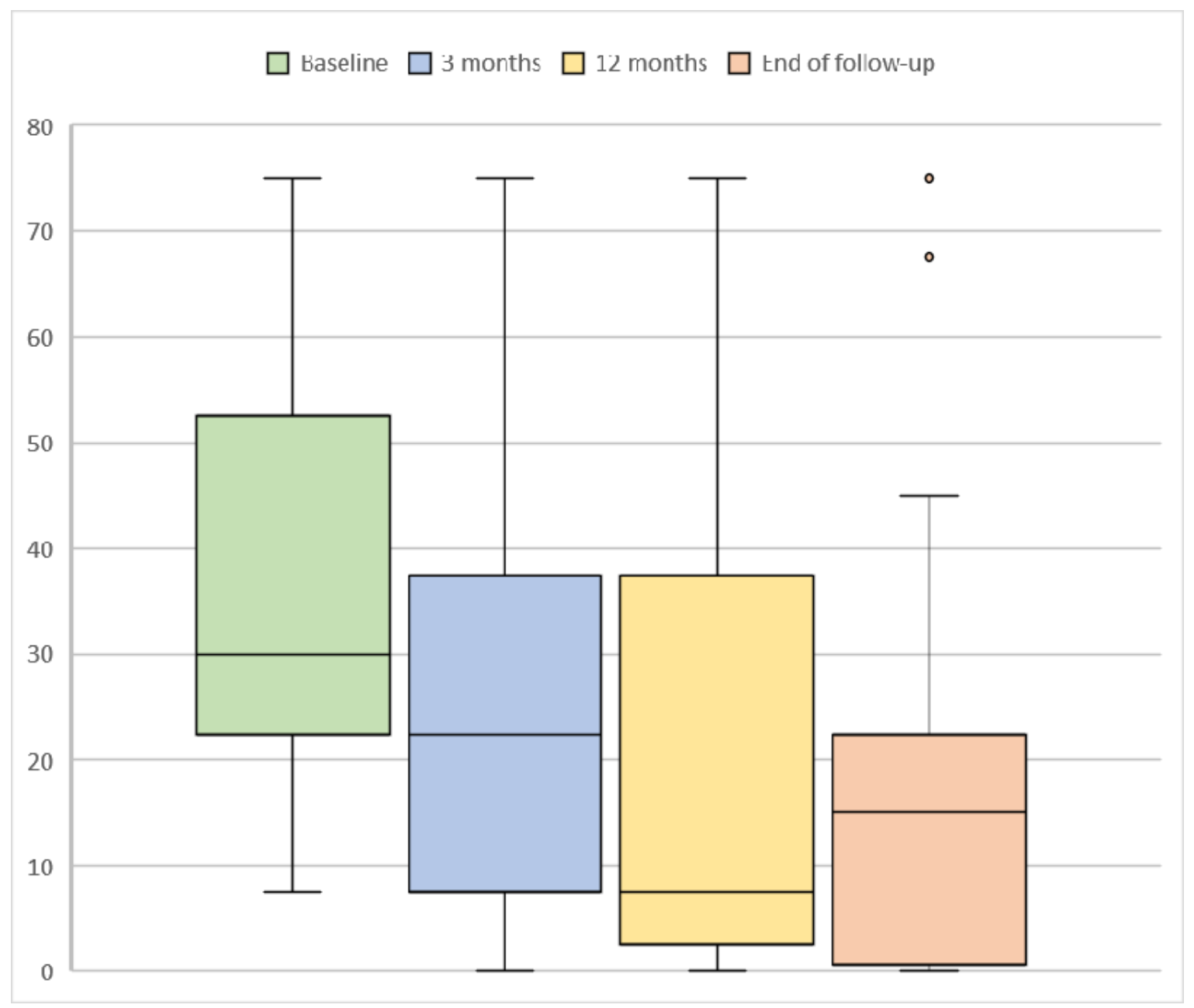

Figure 2. Evolution of weekly number of cluster headache attacks at baseline and after occipital nerve stimulation. Median and ranges are shown. $n=17$ (no missing values between the groups). $p$ values: 0.012 (baseline-3 months), 0.006 (baseline-12 months), 0.041 (baseline-end of follow-up).
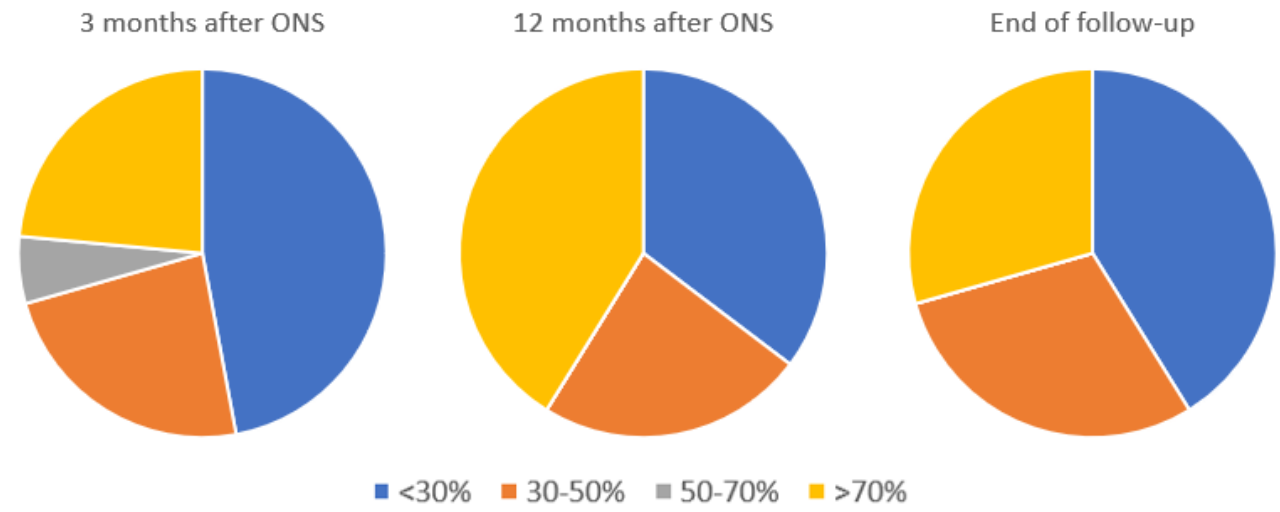

Figure 3. Overall improvement perceived by patients after occipital nerve stimulation (ONS) surgery. $\mathrm{N}=17$ (no missing values between the groups).

\subsection{Preventive Medication Use}

All patients were under preventive medication at baseline. After this intervention, the improvement of $13 / 17(76.5 \%)$ made it possible to decrease their prophylactic medication, 
mainly topiramate, verapamil and lithium, and 3/17 (17.7\%) were able to stop all preventive drugs at the end of follow-up. A decrease in the need for corticotherapy was also observed.

\subsection{Triptan Use}

Concerning the use of symptomatic medication, a decrease in subcutaneous sumatriptan was observed in all responders and 3/17 (17.7\%) patients stopped triptan use. Median weekly triptan use in the responder group at baseline did not differ significantly from the non-responder group (14.0 (11.9-18.2) vs. 14.0 (9.8-21.0), $p=1.000)$. At the end of follow-up, responders achieved a lesser median triptan use per week (7.0 (2.8-7.3)), which did not occur in the group of non-responders $(14.0(9.1-18.6), p=0.002)$.

\subsection{Adverse Events}

During follow-up, 41.2\% (7/17) patients presented adverse effects. There was no mortality. All patients noticed mild paresthesia in scalp areas innervated by the occipital nerve. Stimulation parameters were set according to the patient tolerability. In the postintervention period, the most frequent AE was mild superficial surgical wound infections $(2 / 17,11.8 \%)$. Regarding long-term complications, $11.8 \%(2 / 17)$ presented electrode migration, one patient $(4.6 \%)$ presented infection in the electrode area, another $(5.9 \%)$ reported local pain at the electrode and another (5.9\%) reported hardware dysfunction after trauma. Reintervention was needed for this patient and another eight $(9 / 17,52.9 \%)$ in this latest group, because of battery depletion, all experienced clinical worsening in terms of battery depletion and an improvement after its replacement.

\subsection{Non-Responders}

At the end of follow-up, 6/17 (35.3\%) were non-responders to ONS (i.e., the same or a greater number of weekly attacks). There was no statistically significant difference between non-responders and responders in terms of median $\mathrm{CH}$ duration (5.0 (0.3-18.3) vs. $9.0(4.9-24.2), p=0.462)$, median number of preventive medication used prior to ONS (3.5 (2.7-5.3) vs. $4.0(3.6-6.1), p=0.404)$, median weekly attacks at baseline (33.8 (10.0-67.5) vs. $30.0(18.4-67.5), p=1.000)$ and median years of follow-up (5.0 (2.5-8.2) vs. 7.0 (5.2-9.4), $p=0.256)$.

\section{Discussion}

Regarding our primary endpoint, the weekly attacks' frequency, we observed a median of 15 attacks per week at the end of follow-up. The decline in this parameter improved progressively at the 3rd and 6th month and the greatest reductions were registered one year after ONS surgery, of 7.5 attacks per week, which reached 15 at the end of follow-up. The fact that ONS effectivity appears to slightly decrease over time was also reported by Aibar Duran et al. [19], but, in their study, the decrease in effectiveness was seen at month 6 , and, in our study, it was found later. Despite this fact, our results are hopeful considering that this means a 50\% reduction in attacks at the end of follow-up. As for the VAS, which presented a median of 10 at baseline, the greatest reduction in the intensity of the attacks was reached in the first year (VAS 7) and remained stable at the end of the follow-up (VAS 7). Concerning the overall perceived improvement, we also describe very good results 1 year after ONS implantation, reaching more than $70 \%$ patients with a response to the chronic stimulation. A mild reduction in benefit during longer follow-up, as in weekly attack number, was observed. Triptans and preventive medications were reduced or stopped in all responsive patients, which involves the achievement of a difficult therapeutic objective that has a direct impact on the patients' quality of life. Considering all these parameters, it can be deduced that ONS achieves a sustained reduction in both the weekly attacks' frequency and intensity, with a peak in response after one year of monitoring.

Prior to ONS, nine patients reported a positive response to occipital nerve block and, according to our results, as well as previous studies [20], this was not necessarily a predictor of good response to continuous stimulation with ONS. Of the nine patients who received a 
GON block, those who benefited from this procedure did not correspond with those who improved most with the ONS. As can be seen in Table 1, none of the patients who did not benefit from the trial phase had previously undergone the anaesthetic block.

During the first years of ONS implementation, several studies with short followup periods were published, showing variable results. In the study by Fontaine et al., 10/13 participants did not show a response until a median follow-up of 14.6 months [11]. Similar results were published by Magis et al. (78.6\% were responders, median follow-up 36.8 months) [8]. On the other hand, Burns et al. described only $35.7 \%$ of responders, with a median follow-up of 17.5 months [10]. A recent meta-analysis included eight open studies with a sample of 96 patients, showing a response rate of $34-71 \%$ and a reduction in weekly attacks of $29 \%$ in a follow-up of $1-3$ years [21]. The variability of these results could, in part, be due to the short follow-up and different definitions of responder patient.

Several studies with a longer follow-up have been published in recent years. In their open-label study with $35 \mathrm{drCCH}$, Leone et al. described $66.7 \%$ of responders (50\% reduction in headache number per day) after a follow-up period of 6.1 years [9]. In the second largest cohort with a prolonged follow-up (39.17 months), counting 51 patients, $52.9 \%$ exhibited a response to ONS at final follow-up. In the last months of 2020, the series with the largest cohort of patients to date was published [22]. At the end of follow-up (43.8 months), they reported a reduction in the frequency of attacks of $>50 \%$ in $69 \%$ of patients. Our results are more in line with these longer series than previous ones.

Considering that these patients are refractory to all therapies and suffer from high levels of disability and impact [23], a threshold of a $>30 \%$ decrease in the frequency of attacks is usually considered sufficient to define response according to different studies [24]. In our cohort, at the end of follow-up, and taking the 18 of the 22 patients who were implanted with a definitive ONS into account, $61.1 \%(11 / 18)$ of the patients presented a perceived improvement of more than $30 \%$. Furthermore, almost a third of patients $(27.8 \%)$ were super-responders at the end of follow-up. It is important to highlight these findings because they were drug-resistant patients who had gone through all kinds of therapies without obtaining any benefit, and three of them became almost asymptomatic, with no current preventive treatments and hardly any recurrence of attacks to date, while two other cases transformed into episodic $\mathrm{CH}$.

An important issue that has been commented on in other similar studies is that the improvement in the patients could be related to the described natural evolution from chronic to episodic forms, as well as the placebo effect. However, it is unlikely that we encountered these possibilities, given the chronicity of our patients' disease (12.2 \pm 11.6 years) as well as the rapid worsening in the face of technical problems such as battery depletion or malfunction.

Although the ONS is not an economic treatment [25], the direct and indirect cost generated by the usually young patients diagnosed with $\mathrm{drCCH}$ widely exceeds the cost of this therapy [26]. Adverse events in our series were much lower than those described in previous cohorts $[9,15,17,19,27]$. ONS seems to be a safe technique when implants are conducted in highly specialised centers for those $\mathrm{CH}$ patients who have failed several preventive treatments, and we think it should be offered as the first option to drCCH patients.

Among the strengths of this study are a prolonged follow-up in a third-level hospital and the experience of a multidisciplinary headache team with extensive experience in neurostimulation. The main limitations of the present study include a small population being analyzed, a retrospective, single-center design and a lack of a control group. Another important limitation is the slight variability in the duration of the final follow-up of patients. It should also be noted that, technically, the ONS has evolved considerably in recent years. The more recent implanted devices are different in terms of size, battery life, and electrodes than those implemented at the beginning of the study in 2008.

Our data provide additional supporting evidence for the use of neuromodulatory therapies for $\mathrm{drCCH}$ treatment, although more prospective randomized, double-blind, 
multi-center clinical trials, like the ICON study [28], are needed to assess the effectiveness of ONS in the prevention and treatment for $\mathrm{drCCH}$.

\section{Conclusions}

In summary, our long-term experience provides additional information about the long-term effect of ONS in patients with drCCH. This intervention appears to have a positive effect in decreasing attack frequency and all reported adverse events have been mild, which could make it a valid option when advanced treatment of $\mathrm{CCH}$ is required. Further research is needed to identify patients who are responders to the ONS in order to offer these therapies to properly selected cases.

Author Contributions: Conceptualization J.D.-d.-T.; methodology J.D.-d.-T., J.A.M. and I.d.L.; formal analysis J.D.-d.-T. and J.A.M.; data curation J.D.-d.-T., J.A.M., I.d.L. and J.R.; investigation J.D.-d.-T., J.A.M., J.P.-S., M.L.-L., J.R., I.d.L.; writing—original draft preparation, J.D.-d.-T. and J.A.M.; writingreview and editing, A.G.-M., E.D.-T., J.P.-S., I.d.L., M.L.-L. and J.R.; supervision, A.G.-M. and E.D.-T.; validation J.P.-S., M.L.-L., A.G.-M. and E.D.-T.; funding acquisition J.D.-d.-T. and M.L.-L. All authors have read and agreed to the published version of the manuscript.

Funding: Publication costs and financial support for medical writing were provided by Boston Scientific. The funder was not involved in the study design, collection, analysis, interpretation of data, the writing of this article or the decision to submit it for publication.

Institutional Review Board Statement: The study was conducted in accordance with the Declaration of Helsinki, and the protocol was approved by the local Ethics Committee for Clinical Research of La Paz University hospital (PI-4996).

Informed Consent Statement: Informed consent was obtained from all subjects involved in the study.

Data Availability Statement: Data available on request due to restrictions eg privacy or ethical. The data presented in this study are available on request from the corresponding author. The data are not publicly available due to privacy and ethical reasons.

Acknowledgments: The authors thank Chronic Cluster Headache patients and their families.

Conflicts of Interest: The authors declare no conflict of interest.

\section{References}

1. Arnold, M. Headache Classification Committee of the International Headache Society (IHS) The International Classification of Headache Disorders, 3rd edition. Cephalalgia 2018, 38, 1-211. [CrossRef]

2. May, A.; Schwedt, T.J.; Magis, D.; Pozo-Rosich, P.; Evers, S.; Wang, S.-J. Cluster headache. Nat. Rev. Dis. Primers 2018, 4, 18006. [CrossRef] [PubMed]

3. Mitsikostas, D.D.; Edvinsson, L.; Jensen, R.H.; Katsarava, Z.; Lampl, C.; Negro, A.; Osipova, V.; Paemeleire, K.; Siva, A.; Valade, D. Refractory chronic cluster headache: A consensus statement on clinical definition from the European Headache Federation. $J$. Headache Pain 2014, 15, 79. [CrossRef] [PubMed]

4. Vukovic Cvetkovic, V.; Jensen, R.H. Neurostimulation for the treatment of chronic migraine and cluster headache. Acta Neurol. Scand. 2019, 139, 4-17. [CrossRef]

5. Martelletti, P.; Jensen, R.H.; Antal, A.; Arcioni, R.; Brighina, F.; de Tommaso, M.; Franzini, A.; Fontaine, D.; Heiland, M.; Jürgens, T.P.; et al. Neuromodulation of chronic headaches: Position statement from the European Headache Federation. J. Headache Pain 2013, 14, 86. [CrossRef]

6. Belvís, R.; Irimia, P.; Seijo-Fernández, F.; Paz, J.; García-March, G.; Santos-Lasaosa, S.; Latorre, G.; González-Oria, C.; Rodríguez, R.; Pozo-Rosich, P.; et al. Neuromodulación En Cefaleas y Neuralgias Craneofaciales: Guía de La Sociedad Española de Neurología y de La Sociedad Española de Neurocirugía. Neurologia 2021, 36, 61-79. [CrossRef]

7. Vyas, D.B.; Ho, A.L.; Dadey, D.Y.; Pendharkar, A.V.; Sussman, E.S.; Cowan, R.; Halpern, C.H. Deep brain stimulation for chronic cluster headache: A review. Neuromodulation Technol. Neural Interface 2019, 22, 388-397. [CrossRef]

8. Magis, D.; Bruno, M.A.; Fumal, A.; Gérardy, P.Y.; Hustinx, R.; Laureys, S.; Schoenen, J. Central modulation in cluster headache patients treated with occipital nerve stimulation: An FDG-PET study. BMC Neurol. 2011, 11, 25. [CrossRef]

9. Leone, M.; Proietti Cecchini, A.; Messina, G.; Franzini, A. Long-term occipital nerve stimulation for drug-resistant chronic cluster headache. Cephalalgia 2017, 37, 756-763. [CrossRef]

10. Burns, L.; Watkins, L.; Goadsby, P.J. Treatment of intractable chronic cluster headache by occipital nerve stimulation in 14 patients. Neurology 2009, 72, 341-345. [CrossRef] 
11. Fontaine, D.; Sol, J.C.; Raoul, S.; Fabre, N.; Geraud, G.; Magne, C.; Sakarovitch, C.; Lanteri-Minet, M. Treatment of refractory chronic cluster headache by chronic occipital nerve stimulation. Cephalalgia 2011, 31, 1101-1105. [CrossRef] [PubMed]

12. Robbins, M.S.; Starling, A.J.; Pringsheim, T.M.; Becker, W.J.; Schwedt, T.J. Treatment of cluster headache: The American headache society evidence-based guidelines: Headache. Headache 2016, 56, 1093-1106. [CrossRef]

13. World medical association declaration of Helsinki: Ethical principles for medical research involving human subjects. JAMA 2013, 310, 2191. [CrossRef]

14. Olesen, J. The international classification of headache disorders. 2nd edition (ICHD-II). Revue Neurologique 2005, 161, 689-691. [CrossRef]

15. Popeney, A.; Alo, K.M. Peripheral neurostimulation for the treatment of chronic, disabling transformed migraine. Headache 2003, 43, 369-375. [CrossRef]

16. Slavin, K.V.; Nersesyan, H.; Wess, C. Peripheral neurostimulation for treatment of intractable occipital neuralgia. Neurosurgery 2006, 58, 112-119. [CrossRef]

17. Weiner, R.L.; Reed, K.L. Peripheral neurostimulation for control of intractable occipital neuralgia. Neuromodulation Technol. Neural Interface 1999, 2, 217-221. [CrossRef] [PubMed]

18. Trentman, T.L.; Slavin, K.V.; Freeman, J.A.; Zimmerman, R.S. Occipital nerve stimulator placement via a retromastoid to infraclavicular approach: A technical report. Stereotact. Funct. Neurosurg. 2010, 88, 121-125. [CrossRef]

19. Aibar-Durán, J.A.; Álvarez Holzapfel, M.J.; Rodríguez Rodríguez, R.; Belvis Nieto, R.; Roig Arnall, C.; Molet Teixido, J. Occipital nerve stimulation and deep brain stimulation for refractory cluster headache: A prospective analysis of efficacy over time. $J$. Neurosurg. 2020, 1-8. [CrossRef] [PubMed]

20. Kinfe, T.M.; Schuss, P.; Vatter, H. Occipital nerve block prior to occipital nerve stimulation for refractory chronic migraine and chronic cluster headache: Myth or prediction? Cephalalgia 2015, 35, 359-362. [CrossRef] [PubMed]

21. Cadalso, R.T.; Daugherty, J.; Holmes, C.; Ram, S.; Enciso, R. Efficacy of electrical stimulation of the occipital nerve in intractable primary headache disorders: A systematic review with meta-analyses. J. Oral. Facial. Pain Headache 2018, 32, 40-52. [CrossRef] [PubMed]

22. Leplus, A.; Fontaine, D.; Donnet, A.; Regis, J.; Lucas, C.; Buisset, N.; Blond, S.; Raoul, S.; Guegan-Massardier, E.; Derrey, S.; et al. Long-term efficacy of occipital nerve stimulation for medically intractable cluster headache. Neurosurgery 2020, 373. [CrossRef]

23. Pohl, H.; Gantenbein, A.R.; Sandor, P.S.; Schoenen, J.; Andrée, C. Interictal burden of cluster headache: Results of the EUROLIGHT cluster headache project, an internet-based, cross-sectional study of people with cluster headache. Headache 2020, 60, 360-369. [CrossRef]

24. Fontaine, D.; Blond, S.; Lucas, C.; Regis, J.; Donnet, A.; Derrey, S.; Guegan-Massardier, E.; Jarraya, B.; Dang-Vu, B.; Bourdain, F.; et al. Occipital nerve stimulation improves the quality of life in medically-intractable chronic cluster headache: Results of an observational prospective study. Cephalalgia 2017, 37, 1173-1179. [CrossRef]

25. Mueller, O.; Diener, H.C.; Dammann, P.; Rabe, K.; Hagel, V.; Sure, U.; Gaul, C. Occipital nerve stimulation for intractable chronic cluster headache or migraine: A critical analysis of direct treatment costs and complications. Cephalalgia 2013, 33, $1283-1291$. [CrossRef] [PubMed]

26. Ford, J.H.; Nero, D.; Kim, G.; Chu, B.C.; Fowler, R.; Ahl, J.; Martinez, J.M. Societal burden of cluster headache in the United States: A descriptive economic analysis. J. Med. Econ. 2018, 21, 107-111. [CrossRef]

27. Belvis, R.; Rodríguez, R.; Guasch, M.; Álvarez, M.J.; Molet, J.; Roig, C. Eficacia y seguridad del tratamiento quirúrgico en la cefalea en racimos. Med. Clín. 2020, 154, 75-79. [CrossRef] [PubMed]

28. Wilbrink, L.A.; Teernstra, O.P.M.; Haan, J.; van Zwet, E.W.; Evers, S.M.A.A.; Spincemaille, G.H.; Veltink, P.H.; Mulleners, W.; Brand, R.; Huygen, F.J.P.M.; et al. Occipital nerve stimulation in medically intractable, chronic cluster headache. The ICON study: Rationale and protocol of a randomised trial. Cephalalgia 2013, 33, 1238-1247. [CrossRef] 